\title{
PENGUNGKAPAN LAPORAN KEUANGAN PEMERINTAH DAERAH (STUDI KASUS DI KABUPATEN KEPULAUAN TALAUD)
}

\author{
Muhammad T. Soleman ${ }^{1}$, Winston Pontoh ${ }^{2}$, Novi S. Budiarso ${ }^{3}$ \\ 1,2,3 Jurusan Akuntansi, Fakultas Ekonomi dan Bisnis, Universitas Sam Ratulangi, Jl. Kampus Bahu, Manado, \\ 95115, Indonesia \\ E-mail : solemantaufik@gmail.com
}

\begin{abstract}
This study aims to examine the factors that influence the disclosure of local government financial statements. The population in this study are employees who work in the Regional Development Planning Agency (BAPPEDA) in the Talaud Islands Regency. Data collection techniques using questionnaires. The type of data used is primary data collected by sending questionnaires to respondents. The research method is quantitative, while the analysis technique used is multiple linear regression analysis. This research result shows that Audit Findings and Capital Expenditures affect the disclosure of regional government financial statements, while the balance funds do not have an influence on the disclosure of local government financial statements.
\end{abstract}

Keywords: Disclosure of Financial Statements, Audit Findings, Balancing Funds and Capital Expenditures.

\section{PENDAHULUAN}

Perkembangan otonomi daerah pada saat ini mencerminkan adanya respon masyarakat akan tata kelola pemerintahan yang baik (good government govrnance). Penerapan tata kelola yang baik dalam penyelenggaraan Negara akan terkait erat dengan masalah akuntabilitas dan transparansi khususnya dalam hal pengelolaan keuangan Negara. Hal ini disebabkan karena keuangan Negara menduduki posisi strategis guna mendukung pembangunan bangsa, baik dari segi sifat, jumlah serta pengaruhnya pada kemajuan, ketahanan, dan kestabilan perekonomian bangsa. Oleh sebab itu, Pemerintah daerah wajib secara terus menerus melakukan upaya perbaikan atas aspek transparansi dan akuntabilitas dari pengelolaan keuangannya. Pengelolaan keuangan daerah mencakup aspek teknis khususnya dalam hal peraturan, kelembagaan sistem informasi keuangan, serta peningkatan kualitas sumber daya ( Lubis, 2017).

Tujuan penyajian informasi dalam laporan keuangan salah satunya yaitu untuk menyajikan transparansi, yakni memberi informasi keuangan yang transparan dan jujur kepada seluruh masyarakat. Dengan pengugkapan informasi keuangan yang terbuka ( Transparan ) buat semua pihak dapat mengawasi / melihat pengelolaan keuangan pemerintah tersebut. Konsep pedoman prosedur Pemerintahan menyatakan yakni transparansi mempunyai bagian pengungkapan dan menyediakan informasi yang layak atau sesuai sehingga lebih mudah dicari oleh pengemban kepentingan. Pengungkapan dan penyediaan informasi merupakan poin terpenting dalam laporan keuangan. Sehingga dapat menciptakan tata kelola pemerintahan yang baik (Setyowati, 2016).

\section{TINJAUAN PUSTAKA}

Akuntansi Pemerintah. Akuntansi Pemerintahan merupakan bidang ilmu yang terkait dengan lembaga pemerintahan dan institusi yang tidak bertujuan mencari laba (Mahmudi, 2013). 
Temuan Audit. Harumiati (2014) menunjukkan bahwa terdapat pengaruh signifikan atas temuan audit terhadap pengungkapan laporan keuangan pemerintah.

Dana Perimbangan. Hasil penelitian Setyowati (2017) menunjukkan bahwa dana perimbangan tidak signifikan mempengaruhi pengungkapan laporan keuangan pemerintah.

Belanja Modal. Penelitian ini sejalan dengan Tahar (2015) menunjukkan bahwa belanja modal memiliki pengaruh signifikan terhadap pengungkapan laporan keuangan pemerintah.

\section{METODE PENELITIAN}

Populasi dan Sampel. Populasi penelitian ini adalah seluruh pegawai Badan Perencanaan Pembangunan Daerah ( BAPPEDA ) Pemerintah Kabupaten Kepulauan Talaud yang berjumlah 35 orang. Dalam pengambilan sampel ini menggunakan teknik random sampling yaitu merupakan teknik penetapan sampling secara acak.

\section{Metode analisis}

Asumsi Klasik. Pengujian asumsi klasik bertujuan untuk mengetahui apakah suatu model regresi tersebut baik atau tidak jika digunakan untuk melakukan penaksiran. Dalam penelitian ini digunakan pengujian asumsi klasik yang terdiri dari beberapa jenis pengujian yakni Uji Normalitas, Uji Multikolonieritas, dan Uji Heteroskedasitas ( Rumengan, 2015).

Uji Normalitas. Uji normalitas bertujuan untuk menguji apakah nilai residual pada model regresi berdistribusi normal atau tidak. Model regresi yang baik adalah memiliki nilai residual yang berdistribusi normal. Pengujian data dilakukan melalui pendekatan Kolmogorov-Smirnov (K-S) dengan signifikan (a) adalah > 5\% (Sunyoto, 2012: 84).

Uji Multikolinealitas. Uji Multikolinealitas bertujuan unutuk mengetahui apakah terjadi interkorelasi ( hubungan yang kuat ) antar variable independen. Untuk mengetahui atau mendeteksi suatu gejala Multikolinealitas ini adalah dengan menggunakan metode tolerance dan VIF ( Vartance Inflation Factor ). Uji Multikolinearitas dapat diketahui dengan melihat nilai tolerance (a) > 0,10 dan Variance Inflation Factor (VIF) < 10 (Sunyoto 2012: 79).

Uji Heteroskedastisitas. Uji heteroskedastisitas bertujuan untuk menguji apakah model regresi memiliki ketidaksamaan varians residual. Jika varians dari residual suatu pengamatan ke pengamatan lain tetap disebut homokedasitas, sedangkan untuk varians yang berbeda disebut heteroskedasitas ( Ghozali, 2013 ).

\section{HASIL PENELITIAN DAN PEMBAHASAN}

\subsection{Hasil penelitian}

Dalam penelitian ini pengumpulan data dengan cara wawancara dan membagikan kuesioner. Pembagian kuesioner dimulai pada tanggal 6 agustus sampai 20 agustus 2018, dengan jumlahl kuesioner yang dibagikan sebanyak 50 kuesioner dan yang dikembalikan sebanyak 35 kuesioner. Kuesioner yang di bagikan berjumlah 50 kuesioner, yang bisa diolah ditabel untuk menganalisis data yaitu sebanyak 35 kuesioner. hasil data tabulasi diolah menggunakan program SPSS 16. 
Tabel 1. Hasil uji regresi linear berganda

\begin{tabular}{|c|c|c|c|c|c|c|c|}
\hline \multirow[b]{2}{*}{ Model } & \multicolumn{2}{|c|}{$\begin{array}{l}\text { Unstandardized } \\
\text { Coefficients }\end{array}$} & \multirow{2}{*}{$\begin{array}{c}\begin{array}{c}\text { Standardized } \\
\text { Coefficients }\end{array} \\
\text { Beta }\end{array}$} & \multirow[b]{2}{*}{$\mathbf{t}$} & \multirow[b]{2}{*}{ Sig. } & \multicolumn{2}{|c|}{$\begin{array}{l}\text { Collinearity } \\
\text { Statistics }\end{array}$} \\
\hline & B & Std. Error & & & & Tolerance & VIF \\
\hline 1 (Constant) & -12.844 & 5.661 & & -2.269 & 0.030 & & \\
\hline Temuan Audit & 0.846 & 0.189 & 0.540 & 4.481 & 0.000 & 0.872 & 1.147 \\
\hline $\begin{array}{l}\text { Dana } \\
\text { Perimbangan }\end{array}$ & 0.302 & 0.194 & 0.195 & 1.555 & 0.130 & 0.809 & 1.237 \\
\hline Belanja Modal & 0.430 & 0.200 & 0.280 & 2.147 & 0.040 & 0.747 & 1.339 \\
\hline
\end{tabular}

a. Dependent Variable: Pengungkapan Laporan Keuangan

\subsection{Pembahasan}

Temuan Audit. Bedasarkan hasil uji regresi diketahui bahwa signifikansi temuan audit berada dibawah $5 \%$ dengan nilai t sebesar 4,481 sehingga dapat disimpulkan bahwa temuan audit (X1) mempunyai pengaruh terhadap pengungkapan laporan keuangan pemerintah (Y). Hal ini menunjukkan bahwa semakin tinggi jumlah temuan audit maka semakin baik pengungkapan laporan keuangan pemerintah daerah sesuai dengan hasil penelitian Harumiati (2014).

Dana Perimbangan. Berdasarkan hasil uji regresi diketahui bahwa nilai signifikansi berada diatas 5\% sehingga dapat di simpulkan bahwa tidak terdapat pengaruh dana perimbangan (X2) terhadap pengungkapan laporan keuangan (Y) dimana hasil penelitian ini sesuai dengan hasil dari Setyowati (2017).

Belanja Modal. Berdasarkan hasil uji regresi diketahui bahwa nilai signifikansi berada dibawah 5\% sehingga dapat di simpulkan bahwa terdapat pengaruh belanja modal (X3) terhadap pengungkapan laporan keuangan (Y), dimana semakin tinggi belanja modal pemerintah daerah maka semakin tinggi tingkat pengungkapan informasi yang di lakukan oleh pemerintah daerah. Hasil penelitian ini mendukung hasil penelitian dari Tahar (2015).

\section{KESIMPULAN DAN SARAN}

\subsection{Kesimpulan}

Berdasarkan hasil uji yang dilakukan, memperoleh hasil sebagai berikut. Temuan Audit terdapat pengaruh signifikan pada pengungkapan laporan keuangan pemerintah, dana perimbangan tidak terdapat pengaruh signifikan pada pengungkapan laporan keuangan pemerintah daerah dan belanja modal terdapat pengaruh signifikan terhdap pengungkapan laporan keuangan pemerintah daerah.

\subsection{Saran}

Bagi Pemerintah Hendaknya lebih patuh terhadap Standar Akuntansi Pemerintahan yang berlaku dengan menyajikan informasi laporan keuangan pemerintah selengkap mungkin. Khususnya mengenai pengungkapan wajib dalam laporan laporan keuangan pemerintah daerah, agar transparansi informasi keuangan kepada masyarakat sesuai dengan pertimbangan bahwa rakyat mempunyai hak untuk mengetahui baik secara transparan atas pertanggugjawaban pemerintah dalam pengelolaan sumber daya yang di percayakan dan ketaatanya pada peraturan perundang - undangan. Bagi Peneliti Selanjutnya agar menambah variable lain yang bisa mempunyai pengaruh terhadap pengungkapan laporan keuangan pemerintah daerah, Peneliti selanjutnya dapat memperpanjang waktu dalam penelitian sehingga bisa memperoleh hasil penelitian yang maksimal, peneliti bisa memperbanyak jumlah sampel yang di teliti dan populasi penelitian tidak di khususkan pada dinas BAPPEDA tetapi di perluas pada dinas yang lainnya. 


\section{DAFTAR PUSTAKA}

Amir, Siti. 2014. “Analisis Penerapan PSAK tentang Penyajian Laporan Keuangan pada PT. Bank Sulut Tbk (Persero)" Jurnal EMBA, 2(3), 001-115.

Ghozali, Imam. 2013. Aplikasi Analisis Multivariate Dengan Program IBM SPSS 21. Badan Penerbit Universitas Diponegoro. Semarang.

Hendriyani. Ririn dan Tahar, Afrizal. Analisis Faktor - Faktor Yang Mempengaruhi Tingkat Pengungkapan Laporan Keuangan Pemerintah Provinsi Di Indonesia. Jurnal Bisnis dan Ekonomi. Volime. 25 - 33.

Hillinger, Claude, 2010, "The Crisis and Beyond: Thinking Outside the Box" Ejournal of Kiel Institute, 4(23), 1-63.

Lubis, Nasrul Kahfi. 2017. Faktor Faktor yang Mempengaruhi Transparansi Pelaporan Keuangan dan Pengaruhnya Terhadap Kualitas Pelaporan Keuangan, JURNAL PENELITIAN EKONOMI AKUNTANSI,Volume 1.

Mahmudi. 2013. Akuntansi Sektor Publik.UII Press. Yogyakarta.

Payamta dan Harumiati, Yayuk. 2014. Pengaruh Karakteristik Pemerintah Daerah dan

Temuan Audit BPK Terhadap Kinerja Pemerintah Daerah Kabupaten / Kota Di

Indonesia Tahun Anggaran 2011. Jurnal Akuntansi dan Pendidikan. Volime. 3.

Priharjanto. Akhmad. 2012. Pengaruh Temuan, Tingkat Penyimpangan, Opini Audit dan

Setyowati. Lilis. 2016. Determain Yang Mempengaruhi Pengungkapan Laporan Keuangan Pemerintah Daerah. Jurnal Bisnis dan Manajemen. Volume. (1) : 45 - 62.

Simbola, Uliarta. Agnecia Henny. 2015. Pengaruh Karakteristik Pemerintah Daerah Terhadap Tingkat Pengungkapan Laporan Keuangan Di Seluruh Provinsi Indonesia. Jurnal. Volume. 30 (1) : 54 - 70.

Sunyoto, Danang. 2012. Model Analisis Jalur untuk Riset Ekonomi.Yrama Widya. Bandung

Sunyoto, Danang. 2012. Uji Validitas dan Reabilitas, Asumsi Klasik untuk Kesehatan, Cetakan 1. Nuha Medika. Yogyakarta.

Susanti, Devilia. 2016. Pengaruh Karakteristik Pemerintah Daerah, Opini Audit dan Temuan Audit Terhadap Kinerja Pemerintah Daerah. ( Studi pada Pemerintah Kabupaten I Kota Di Sumatera Tahun 2010 - 2013 ). Skripsi. Umiversitas Jambi. 